average Esquimaux by twenty-five years; the inhabitants of the unhealthy coast towns of South America survive the Gauchos who live a healthy outdoor life; the Hindus attain a surprising age, considering their penchant for betel poison and their great poverty. In Europe, the southern nations (Greece, Spain, France) are the most favoured as to longevity. England, with a population of $27,483,490$, has 146 centenarians; Spain, with a population of $18,000,000$, has 401 .

Accimatisation a mere Question of Hygiene.

Although obliged to greatly curtail the adducible evidence. I venture to hope that the facts set forth in this paper will suffice to prove: First, that European emigrants can live and perpetuate their kind in tropical regions; secondly, that the difficulties in the way of colonisation are not due to climate, but to parasitism; thirdly, that acclimatisation is, to a great extent, a mere question of hygiene.

If colonisation in the past has proved to be a work of mere destruction, it is not a reason to suppose that it must be so in the future. The very failures of the past, if their meaning be clearly apprehended, will prove useful guides. Our greatest achievements are the results of many failures.

Of course, we must not forget that every attempt at colonisation is a campaign not only against man, but against a host of minute living organisms far more fearful.

In last year's expedition to Madagascar, only 7 men were killed by the Hovas and 94 wounded; but the deaths due to disease numbered 6,0ว०, the French lost no fewer than 50,000 out of 60,000 from yellow fever.

The first and most important step towards success is the explosion of the old baneful theories which would only operate by obstructing the adoption of appropriate measures. Europeans going to tropical countries must be of robust constitution and in perfect health. To think that the weaklings and those from malarious districts stand a better chance is an absurd mistake. But physical defects are not the only disabilities; personal habits are of the utmost importance ; temperance and morality are powerful weapons in the struggle for life. Arnold was right in saying:"Drink has cost England more graves in the East than all our wars since Clive." Sexual immorality, under the influence of a tropical climate, and in the presence of a native servile and morally undeveloped population, rises to a climax unknown amid the restraints of home life, and becomes one of the most potent causes of physical prostration.

Of the greatest importance is the choice of healthy localities. Even in the most sickly regions there are healthy tracts of greater or lesser extent. The general salubrity of a place may be fairly ascertained from the physical standard of its inhabitants.

The fertility of the land and the conveniences of trade have generally determined the location of settlements on the deadly alluvial soils at the mouth of rivers. Towns thus built in the very worst places in considera tion of their apparent value, but totally regardless of their qualities with reference to health, are greatly responsible for the reputation of unhealthiness which is associated with tropical countries.

The sanitation of the unhealthy tracts in tropical lands may seem at first a hopeless task, but intelligence, energy and science will surely triumph. The genius of man which has united Transcontinental seas and tunnelled mountains, which has changed the course of rivers and made vast regions rainless by denuding them of their forests, which has obliged the earth to produce almost only cultivated plants and domestic animals, and which has grasped the whole globe in awonderful mesh of electric feelers, can undoubtedly turn to ts advantage the vast and rich territories which lie within the tropical belt. ${ }^{20}$

The Evolution of Man.

Europeans who settle in tropical countries must not expect to remain unchanged from generation to generation. Even when there is no intercrossing, although the main features may persist for a long while, the new surroundings soon give their own print. This is clearly shown by the Jews, who retain their original features, but who also bear the stamp of the country in which they live. In all the Colonies where Europeans have settled, we find they have altered in temperament, ideas, and bodily features. The change is slow at

20 The tropical zone comprises more than one-th rd of the surface of the globe. first, because fresh blood constantly streams in from the Mother Country, and perpetuates the original characters, but, as the colony grows older, the immigration lessens, and the new settlers diverge further and further from their original type.

We have no reason to dread this evolution, it is the outcome of acclimatisation, and when we consider what splendid races (the Sikh of India, for example) inhabit the most favoured tropical regions, we must come to the conclusion that it can only lead to the development of new people, certainly not inferior to the noblest specimens of existing humanity.

Nevertheless, when we consider that man, modifying surroundings and substituting his selection for that of Nature, has been able to produce endless varieties of domestic animals which would never have come into existence under natural conditions, and would soon revert through atavism to the original type (as witness the wild horse), or perish out of their artificial surroundings, we must certainly believe that he can escape many of those influences which irresistibly modify all other organic beings.

From the moment when the first skin was used as a covering and the first fire blazed at will, man was no longer a slave to the universal evolution, and advancing civilisation will enable him more and more to keep himself in harmony with Nature-not by bodily changes, but by greater strides in intellectual power.

\section{HYPERPYREXIA IN MEASLES.}

BY T. M. ALLISON, M.D., Newcastle-on-Tyne.

ON December Ioth, 1896, I was asked to see a well-nourished girl, aged 15 months, with a history of whooping-cough during the previous five weeks. She was suffering from bronchopneumonia, the respirations being 70, and the temperature 104. The face was somewhat livid, and the eyelids glued together with secretion. I ordered medicine and a hot bath, and in the evening the temperature was $102^{\circ}$ and the respirations 60.

Next day a rash was visible on the forehead at the roots of the hair; the temperature was $104.2^{\circ}$, and the respirations very shallow and rapid.

At night the nurse sent me word that the temperature was I09. On arrival I learnt that the child had had two slight convulsions, and had been given a hot bath. On putting my thermometer into the axilla, I found it to register ${ }^{\circ} 7^{\circ}$, whilst the nurse showed me her thermometer still registering $109^{\circ}$. This had been taken before the bath.

The patient was cyanotic, restless, and apparently unconscious. The rash had disappeared. The breathing was extremely quick for five or six respirations, and then came a long pause, followed by a struggle to get rid of the bronchial secretion, which threatened to choke her. During respiration hurried harsh breath sounds were present over the left chest behind, whilst abundant moist râles were heard in addition over the right. Both sides were resonant, with the exception of a slight area of dulness at the base of the right lung.

I gave antifebrin grs.ijss by the mouth, but as anything swallowed tended to set up an attempt at whooping-cough (seemingly overshadowed by the pulmonary condition) I administered atropine hypodermically, which checked secretion and calmed and regulated the breathing. On now rubbing the body back and front with ice the temperature was brought down, but it quickly went up again to $109^{\circ}$ by the nurse's thermometer and to $109.2^{\circ}$ by mine, both records being taken in the axilla. Ice was again applied to the body, and as the temperature fell the forehead was seen first to become flushed, and then the characteristic rash of measles followed, and spread slowly down the face, whilst the moaning of the child showed that consciousness was returning. The general condition became much easier for a time, but the breathing suddenly quickened and stopped, the rash disappeared, and the child expired.

Although high fever is not unknown in the measles of adolescence. yet a temperature of $109^{\circ}$ is rare in that disease in childhood. 